\section{Ultrasound Supplemented by Sialendoscopy: Diagnostic Value in Sialolithiasis
Sialendoscopy: Diagnostic Value in}

\author{
Miguel Goncalves, MD', Konstantinos Mantsopoulos, MD', \\ Mirco Schapher, MD', Heinrich Iro, MD', and Michael Koch, MD'
}

Otolaryngology-

Head and Neck Surgery

2018, Vol. 159(3) 449-455

(C) American Academy of

Otolaryngology-Head and Neck

Surgery Foundation 2018

Reprints and permission:

sagepub.com/journalsPermissions.nav DOI: $10.1177 / 0194599818775946$ http://otojournal.org

๑SAGE
No sponsorships or competing interests have been disclosed for this article.

\begin{abstract}
Objective. To assess the value of ultrasound, if indicated, supplemented by sialendoscopy, in the diagnosis of sialolithiasis.

Study Design. Retrospective study.

Setting. Referring center for salivary gland diseases.
\end{abstract}

Subjects and Methods. All patients who presented with a suspected diagnosis of obstructive sialopathy between January $201 \mathrm{I}$ and April 2017 and had not undergone any treatment were retrospectively evaluated. A total of 2052 patients and 2277 glands were included in the study. Ultrasound examinations were carried out initially and followed by sialendoscopy in all cases. Direct demonstration of sialothiasis by sialendoscopy, transoral ductal surgery, and discharge of concrements/observation of fragments during sialendoscopy after extracorporeal shock-wave lithotripsy were regarded as definitive evidence of sialolithiasis.

Results. Ultrasound had an accuracy, sensitivity, specificity, positive predictive value, and negative predictive value of $94.77 \%, 94.91 \%, 94.57 \%, 96.14 \%$, and $92.89 \%$, respectively, for the diagnosis of sialolithiasis. All false-positive findings were correctly diagnosed, and in all false-negative findings, stones/fragments were visualized by sialendoscopy. Over $95 \%$ of the false-negative findings in major salivary glands (64/67) had visible ductal dilation in sonography, and in $73.1 \%$, the stones not detected on ultrasound were located in the distal part of the duct, which is easily accessible with the sialendoscope.

Conclusion. This study shows that sialolithiasis can be diagnosed using ultrasonography with a high degree of certainty. If supplemented by sialendoscopy, the correct diagnosis could be established in virtually all cases of sialolithiasis. Ultrasound supplemented by sialendoscopy has the potential to serve as an alternative diagnostic standard in the future.

\section{Keywords}

salivary, stones, glands, submandibular, parotid, ultrasound, sialolithiasis, sialendoscopy
Received November 28, 20I7; revised April II, 2018; accepted April 19, 2018.

$\mathrm{S}$ ialolithiasis is the most frequent cause of obstructive sialadenopathy. ${ }^{1-4}$ Over $50 \%$ of salivary stones cannot clinically be reliably assessed by palpation due to size $(<3 \mathrm{~mm})$ and/or location. ${ }^{5}$ There is as yet no standard examination method for establishing a diagnosis of sialolithiasis, although a wide variety of imaging procedures are applicable. Plain conventional radiographic examinations, computed tomography (CT), digital subtraction sialography, magnetic resonance (MR) sialography, and ultrasonography have been used with variable degrees of diagnostic success. ${ }^{6-19}$ Computed tomography, particularly cone-beam CT (CBCT), is today the preferred examination modality, with reported sensitivity and specificity values of up to $98.85 \% .{ }^{8,9}$ The logistics, costs, and radiation exposure involved in the method are inherent limitations and disadvantages, however. Although MR sialography has been used successfully, with sensitivity and specificity rates $>90 \%$, it has not become established in routine clinical practice due to its costs and efforts. $13,16,17$

Ultrasonography is becoming increasingly important as a diagnostic tool in sialolithiasis, with a sensitivity of $77 \%$ to $95 \%$ and a specificity of $80 \%$ to $100 \%$. $^{12,14,15,18-21}$ Ultrasound is a dynamic real-time method that does not involve radiation exposure and can be carried out costeffectively by clinicians themselves. Sialendoscopy is now an established method for managing obstructive diseases in the major salivary glands. It has been shown that sialendoscopy can detect stones that are not visualized using other imaging tools. ${ }^{3,22}$ On the basis of our group's experience, we would argue that the diagnostic precision of highresolution B-scan ultrasound can be supplemented with sialendoscopy, making it possible to establish an accurate

'Department of Otorhinolaryngology, Head and Neck Surgery, University of Erlangen-Nuremberg, Erlangen, Germany

\section{Corresponding Author:}

Michael Koch, MD, Department of Otorhinolaryngology, Head and Neck

Surgery, University of Erlangen-Nuremberg, Germany, Waldstrasse I,

91054 Erlangen, Germany.

Email: michael.koch@uk-erlangen.de 
diagnosis in virtually every case of sialolithiasis. The objective of this study was to assess the value of ultrasound supplemented by sialendoscopy and propose this as an alternative standard for diagnosing sialolithiasis.

\section{Methods}

This retrospective study was carried out at the Department of Otorhinolaryngology, Head and Neck Surgery of the University of Erlangen-Nuremberg, Germany. Approval for the study was obtained from the local institutional review board of the Friedrich-Alexander University of ErlangenNuremberg, and informed consent was obtained from all study participants.

All patients who presented with a suspected diagnosis of obstructive sialopathy between January 2011 and April 2017 were evaluated. To exclude bias, only patients who were presenting in the department for the first time and had not undergone previous treatment elsewhere were considered. A total of 2052 patients and 2277 glands were included in the study. The patients' mean age was $46.8 \pm$ 16.1 years (range, $1-89$ years); $52.4 \%$ were women (1076/ $2052)$, and $47.6 \%$ were men $(976 / 2052)$.

Clinical criteria for a suspected diagnosis of obstructive sialopathy were periprandial swelling of the salivary glands, recurrent unclear pain in the area of the salivary glands, enlargement of the major salivary glands, and recurrent sialadenitis. All patients underwent an ultrasound examination of the submandibular gland (SMG), sublingual gland (SLG), and parotid gland (PG). The examination was carried out using high-end ultrasound devices (Siemens ACUSON S2000 and S3000; Siemens Medical Solutions USA, Malvern, Pennsylvania). Every patient was examined by at least 2 otolaryngology specialists with several years of experience in ultrasonography and in the treatment of salivary gland diseases. The sonographic examination was routinely recorded. The diagnosis was established by a pretherapeutic ultrasound examination and was not revised retrospectively to exclude any bias. Stimulation of glandular secretion with oral administration of vitamin $\mathrm{C}$ was used to enhance the findings in patients with unclear ductal obstruction. ${ }^{23}$ Hyperechoism with distal signal loss in the duct was evaluated as a sign of sialolithiasis. The stones were classified according to their location as intraparenchymal stones, proximal/hilar stones, stones in the middle third, and stones in the distal ductal system, including the papillary region, on the basis of replicable sonographic landmarks, as already described in a previous study. ${ }^{12}$

All patients with signs of obstructive sialopathy - with or without sonographic suspicion of sialolithiasis - underwent sialendoscopy to establish the diagnosis and plan and/or carry out the appropriate therapy. Treatment was performed in accordance with established algorithms, which include interventional sialendoscopy, transoral ductal incision, extracorporeal shock-wave lithotripsy (ESWL), intraductal pneumatic lithotripsy, or a combination of these. ${ }^{24,25}$

The definitive diagnosis of sialolithiasis, and the reference standard used, was direct visualization of the stone
Table I. Diagnosis of Sialolithiasis with Ultrasound: CrossTabulation in All Glands, Submandibular Gland, and Parotid Gland.

Characteristic

Sialolithiasis, No. Sialolithiasis, No.

All glands $(N=2277)^{a}$
US positive $(n=1320)$
US negative $(n=957)$
Parotid gland $(n=966)$
US positive $(n=28 I)$
US negative $(n=685)$
Submandibular gland $(n=1307)$
US positive $(n=1036)$
US negative $(n=27 I)$

$\begin{array}{rr}1337 & 940 \\ 1269 & 51 \\ 68 & 889 \\ 273 & 693 \\ 256 & 25 \\ 17 & 668 \\ 1060 & 247 \\ 1010 & 26\end{array}$

Abbreviation: US, ultrasound.

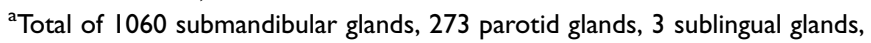
and I case in a heterotopic accessory gland.

during diagnostic/interventional sialendoscopy. With intraparenchymal stones that could not initially be visualized using sialendoscopy, ESWL was used to disintegrate and/or mobilize the stones. ESWL proved to convert invisible/inaccessible stones into visible/accessible stones. ${ }^{26}$ Passage of fragments in the saliva after stone fragmentation and evidence of stones/fragments on follow-up sialendoscopy after ESWL were used as evidence of sialolithiasis defining the true positives. ${ }^{26}$ Simultaneous sialendoscopy and ultrasound were used to clarify diagnoses in which false-positive ultrasound findings were suspected or to diagnose and locate stones precisely within the ductal system. This combination of diagnostic methods was very useful for determining whether hyperechoism had an extraductal or extraparenchymal location and/or was present in combination with sialolithiasis.

Statistical analysis was performed using SPSS Statistics for Windows, version 22.0 (SPSS, Inc, an IBM Company, Chicago, Illinois). Data are given as means plus or minus standard deviation, with values for accuracy, sensitivity, specificity, and range, along with the positive predictive value (PPV) and negative predictive value (NPV).

\section{Results}

Of the total of 2277 glands (2052 patients) retrospectively investigated, 1307 (57.4\%) were SMGs, 966 (42.4\%) were PGs, 3 were SLGs $(0.1 \%)$, and 1 was a heterotopic accessory gland of the parotid gland (Tables I and 2).

Ultrasonography raised a suspicion of sialolithiasis in 1320 of the 2277 glands (57.97\%; 1023 SMGs, 3 SLGs, and 273 PGs). Using our reference standard, sialolithiasis was diagnosed in 1337 of the 2277 glands $(58.72 \%$; 1060 SMGs, 273 PGs, 3 SLGs, and 1 in a heterotopic accessory gland of the parotid gland).

The stones diagnosed with ultrasonography had a mean size of $6.3 \pm 3.1 \mathrm{~mm}$ (range, $1.8-20.0 \mathrm{~mm}$ ) in the $\mathrm{PG}$ and $7.4 \pm 3.8 \mathrm{~mm}$ (range, $1.5-37.0$ ) in the SMG. 
Table 2. Distribution of Stones in the Various Segments of the Efferent Duct of the Submandibular Gland or Parotid Gland When Sialolithiasis Was Actually Present.

\begin{tabular}{|c|c|c|c|c|}
\hline \multirow[b]{2}{*}{ Location of Sialolith } & \multicolumn{2}{|c|}{ Submandibular Gland, No. (\%) } & \multicolumn{2}{|c|}{ Parotid Gland, No. (\%) } \\
\hline & $\begin{array}{l}\text { False-Negative Results, } \\
\qquad \mathrm{n}=50(100 \%)\end{array}$ & $\begin{array}{l}\text { Total Glands with Stones, } \\
\qquad \mathrm{n}=1060(100 \%)\end{array}$ & $\begin{array}{l}\text { False-Negative Results, } \\
\qquad n=17(100 \%)\end{array}$ & $\begin{array}{l}\text { Total Glands with Stones, } \\
\qquad n=273(100 \%)\end{array}$ \\
\hline Distal & $40(80)$ & $26 \mid(25)$ & $9(53)$ & $110(40)$ \\
\hline Middle third & $4(8)$ & $64(6)$ & $2(12)$ & $30(\mathrm{II})$ \\
\hline Several locations & $3(6)$ & $178(17)$ & 0 & $4 \mid(15)$ \\
\hline
\end{tabular}

Table 3. Test Performance Metrics for Ultrasound in Sialolithiasis.

\begin{tabular}{lccc}
\hline $\begin{array}{l}\text { Diagnostic Test } \\
\text { Performance Metric }\end{array}$ & $\begin{array}{c}\text { Value Overall } \\
(95 \% \mathrm{Cl})\end{array}$ & $\begin{array}{c}\text { Value for Submandibular } \\
\text { Gland }(95 \% \mathrm{Cl})\end{array}$ & $\begin{array}{c}\text { Value for Parotid } \\
\mathrm{Gland}(95 \% \mathrm{Cl})\end{array}$ \\
\hline Sensitivity, \% & $94.9(93.6-96.0)$ & $95.3(93.8-96.5)$ & $93.8(90.2-96.3)$ \\
Specificity, \% & $94.6(92.9-95.9)$ & $89.5(85.0-93.0)$ & $96.4(94.7-97.7)$ \\
Positive likelihood ratio & $17.49(13.39-22.85)$ & $9.05(6.29-13.02)$ & $25.99(17.67-38.24)$ \\
Negative likelihood ratio & $0.054(0.043-0.068)$ & $0.05(0.04-0.07)$ & $0.06(0.04-0.10)$ \\
Positive predictive value, \% & $96.1(95.0-97.0)$ & $97.5(96.4-98.2)$ & $91.1(87.4-93.8)$ \\
Negative predictive value, \% & $92.9(91.2-94.3)$ & $81.6(77.1-85.3)$ & $97.5(96.1-98.4)$ \\
Accuracy, \% & $94.8(93.8-95.7)$ & $94.2(92.8-95.4)$ & $95.7(94.2-96.9)$ \\
False-negative rate, \% & $5.1(4-6.4)$ & $4.7(3.5-6.2)$ & $6.2(3.7-9.8)$ \\
False-negative findings, \% & 3.0 & 3.8 & 1.8 \\
False-positive rate, \% & $5.4(4.1-7.1)$ & $10.5(7-15)$ & $3.6(2.3-5.3)$ \\
False-positive findings, \% & 2.4 & 2.0 & 2.6 \\
\hline
\end{tabular}

Abbreviation: $\mathrm{Cl}$, confidence interval.

Anatomic location of sialoliths within the salivary ductal system is shown in Table 2. In submandibular glands, $46 \%$ were located in the hilum and $25 \%$ in the distal duct. In the parotid glands, this was reversed, with the distal duct followed by the hilum as the most common locations $(40 \%$ and $27 \%$, respectively).

A total of 68 false-negative findings (50 in the SMG, 17 in the PG, and 1 in the sublingual gland) and 51 falsepositive findings were identified for ultrasound (26 in the SMG and 25 in the PG) (Tables I-3).

Diagnostic test metrics, including accuracy, sensitivity, specificity, PPV, NPV, false-positive rates, and falsenegative rates of sonography as a single-mode examination tool, are provided in Table 3.

Sialendoscopy was valuable in particular in cases of unclear, false-positive, or false-negative findings on ultrasound. False-positive and false-negative findings on ultrasound were $<4 \%$ (Tables I and 3). The correct diagnosis was established in all cases by direct stone identification with sialendoscopy or by excluding sialolithiasis by locating a questionable hyperechoic reflex in an extraductal/extraparenchymal site. Deep parenchymal stones initially not visible by sialendoscopy were seen (fragments) in the sialendoscopy following ESWL, demonstrating the original deep parenchymal hyperechoism as a sialolith. ${ }^{12,26}$

The stones in the SMG that were only discovered on sialendoscopy (false-negative results) were usually small (2.27 $\pm 0.65 \mathrm{~mm}$; range, $1.5-3.0 \mathrm{~mm}$ ), soft in consistency, and in $80 \%$ of the cases located in the most distal part of the efferent duct (Table 2; Figure IA,B and Figure 2). Overall, $15.3 \%(40 / 261)$ of stones in the distal part of Wharton's duct, $6.25 \%(4 / 64)$ of those in the middle third, but only $0.6 \%(3 / 492)$ of those in the proximal part of Wharton's duct were not detectable on ultrasound (Table 2). In the presence of multiple/multilocular sialolithiasis, stones were not detected in $1.6 \%$ of the patients (3/178). Intraparencyhmal stones were always detected on ultrasound. Accompanying duct dilation was identified in $94 \%$, and the diameter of the duct was $3.5 \pm 1.2 \mathrm{~mm}$ (range, $1.4-7.0 \mathrm{~mm}$ ). Only $6 \%$ of the false-negative findings $(3 / 50)$ showed no signs of ductal congestion.

In the PG, false-negative results were obtained in $1.76 \%$, with the stones being located distally in most cases $(52.9 \%)$. Of these, $8.1 \%(9 / 110)$ escaped ultrasound detection. 


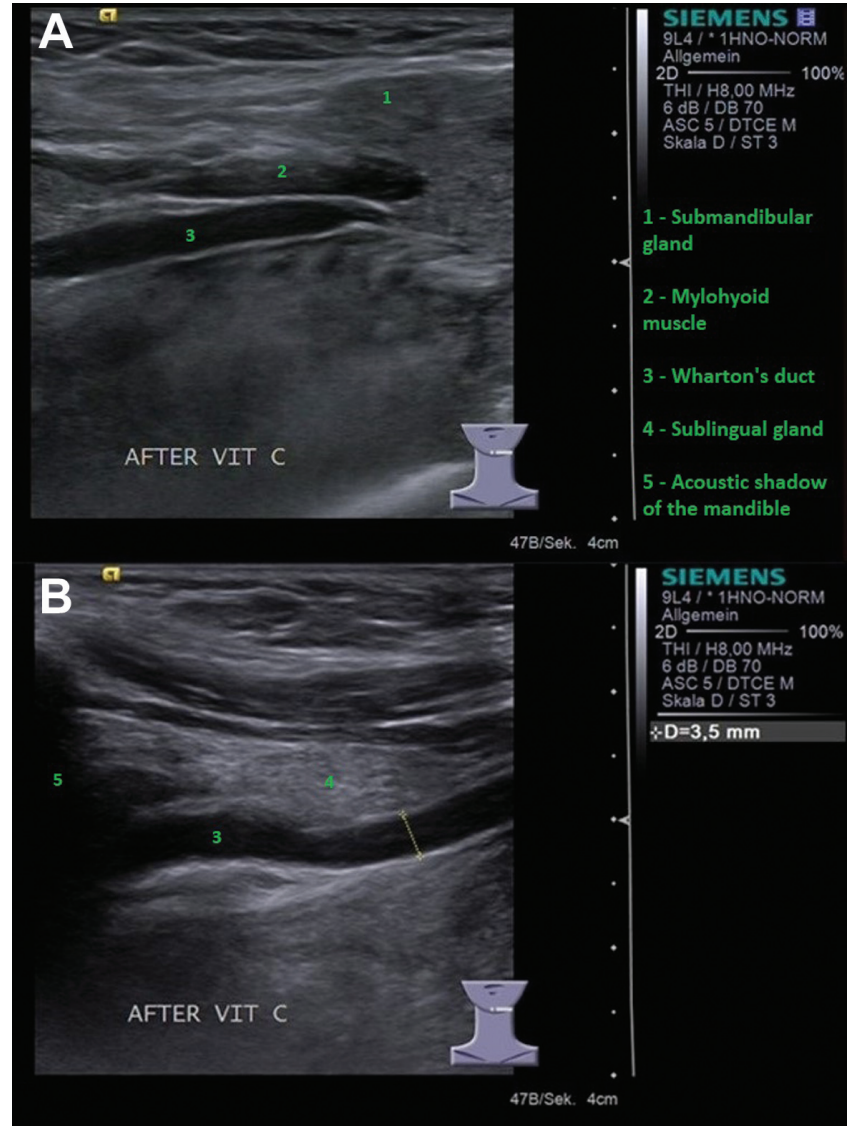

Figure I. False-negative finding in submandibular gland sialolithiasis: sonography shows a dilated Wharton's duct (diameter $3.5 \mathrm{~mm}$; A, B). The most distal part of the duct could not be adequately visualized due to the acoustic shadow of the mandible (B).

Intraparenchymal stones and multiple/multilocular sialoliths were, however, detectable with ultrasound in all cases (Table 2). Stones that were visualized only with sialendoscopy were $3.0 \pm 0.82 \mathrm{~mm}$ in size (range, $1.5-4.0 \mathrm{~mm}$ ). All false-negative findings in the parotid gland showed ductal dilation as sign of obstructive sialopathy (maximum diameter of the congested duct: $2.9 \pm 1.4 \mathrm{~mm}$; range, 1.2-6.0 $\mathrm{mm})$.

Analyzing the SMG and PG together showed that most of the stones not detected by ultrasound (73.1\%; 40 in SMG and 9 in the PG of 67 false negatives for both glands) were located in the distal part of the duct (Table 2), which is also the part of the ductal system best accessible with the sialendoscope.

One of the 3 sialolithiasis cases of the SLG was a false negative in ultrasound.

With the false-positive findings, the ultrasound diagnosis of sialolithiasis was revised in all cases after sialendoscopy was performed. If sialendoscopy also did not reveal the correct diagnosis concerning an unclear hyperechoism, further radiologic imaging (eg, MR imaging [MRI]) was indicated.

A total of 51 false-positives were identified (25 in the PG and 26 in the SMG). In the PG, 32\% (8/25) were extraductal calcifications; $64 \%(16 / 25)$ were related to stenosis

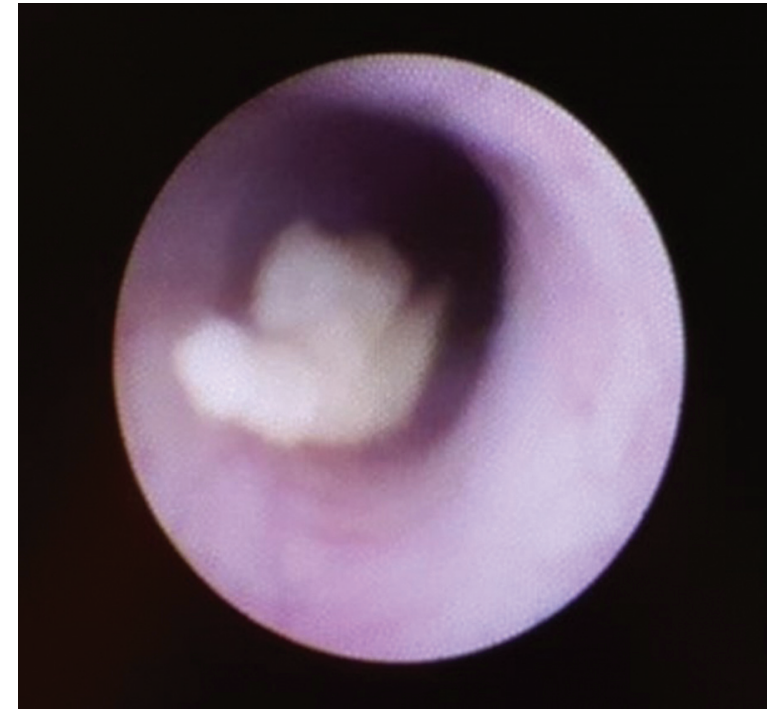

Figure 2. A small, mobile stone with a size of 1.5 to $2 \mathrm{~mm}$ is visualized by sialendoscopy only in the most distal part of the duct near the papilla and removed near the hilum by basket extraction.

(Figure 3A,B and Figure 4A,B), scars, and/or ductal inflammation; and in 1 case $(4 \%, 1 / 25)$, the finding was due to air bubbles trapped in Stensen's duct. In the SMG, 26.9\% of the false positives (7/26) were extraductal calcifications; $69.2 \%(18 / 26)$ were caused by stenoses, scars, and/or ductal inflammation; and $3.8 \%(1 / 26)$ were due to air bubbles trapped in Wharton's duct. In 7 cases, the definitive diagnosis was not clear with ultrasound, and MRI was therefore indicated. These cases proved to be due to phleboliths (SMG, $\mathrm{n}=1)$, vascular malformations (SMG and PG, $\mathrm{n}=$ 1), intratendinous calcifications within the mylohyoid muscle (SMG, $\mathrm{n}=1$ ) and masseter muscle (PG, $\mathrm{n}=1)$, calcified lymph nodes $(\mathrm{PG}, \mathrm{n}=1)$, and a calcified tumor adjacent to the duct (PG, $\mathrm{n}=1)$.

\section{Discussion}

These results confirm the excellent diagnostic value of ultrasonography in sialolithiasis, with an accuracy, sensitivity, specificity, PPV, and NPV of 94.91\%, 94.57\%, 96.14\%, $92.89 \%$, and $94.77 \%$, respectively (Table 3).

The value of ultrasound has already been examined in various publications, but nearly all of these have only included smaller numbers of cases $(<100)$. Values for sensitivity and specificity in the range of $73 \%$ to $77 \%$ and $90 \%$ to $95 \%$, respectively, have been reported. ${ }^{14,15,18-21}$ A recent study by our own group demonstrated the value of ultrasound in more than 600 patients, with overall sensitivity and specificity rates of $94.7 \%$ and $97.4 \%$, respectively. ${ }^{12}$

Even in experienced hands, ultrasound examinations are associated with minor inaccuracies, indicated by a falsenegative rate and a false-positive rate of, respectively, 5.1\% and $5.4 \%$. One of the obstacles with ultrasound in the SMG is the acoustic shadow created by the mandible (Figure IA,B and Figure 2). In addition, the large distance from transducer to the floor of the mouth, particularly at the 


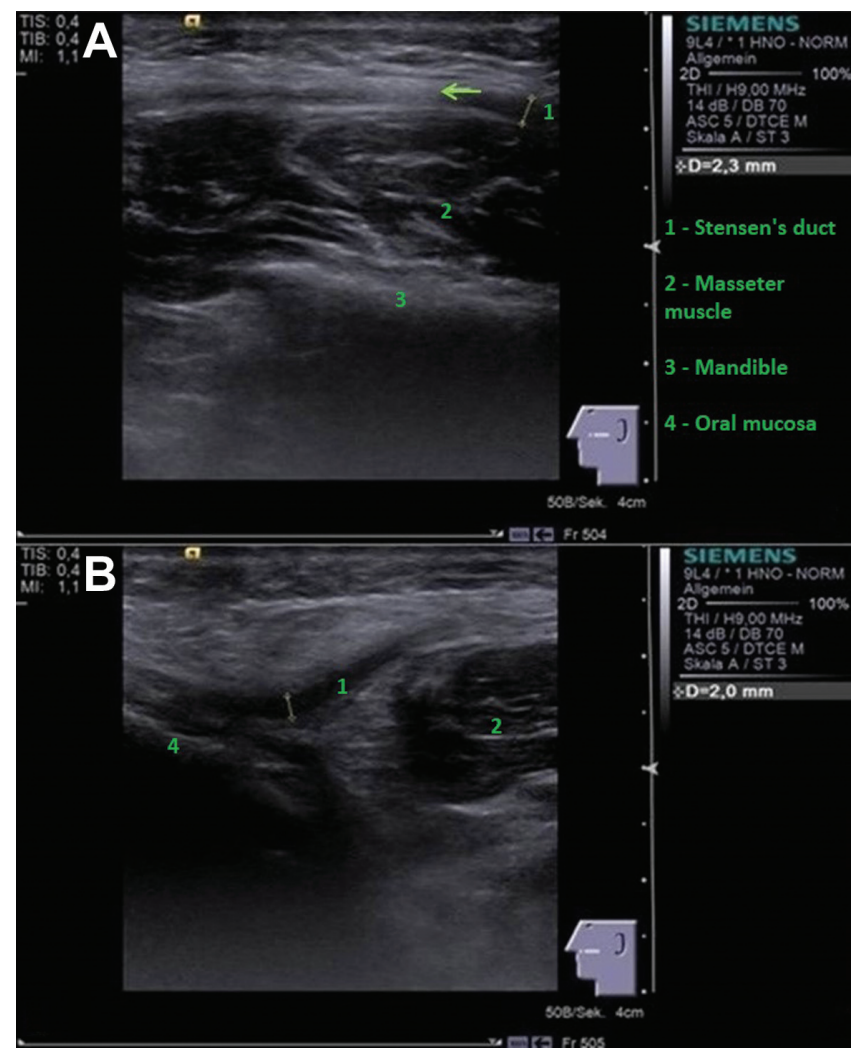

Figure 3. False-positive and false-negative finding in parotid gland: weak hyperechoic reflex without a clear acoustic shadow in the middle third of the duct (green arrow, A) with dilation proximal $(2.3 \mathrm{~mm}, \mathrm{~A})$ and distal $(2.0 \mathrm{~mm}, \mathrm{~B})$.

ostium, may prevent visualization, particularly of stones located in the distal Wharton's duct. Competing hyperechoism caused by fibrotic and/or calcified tissue next to the duct or by air on the surface of the mucosa may also be mistaken for sialoliths. Stones in the PG may be overlooked due to competing hyperechoism associated with the complex anatomy along Stensen's duct. Teeth, hyperechoism caused by changes in impedance at the oral mucosal surface, or even air bubbles may be misdiagnosed as stones, as is the case in intraductal fibrosis (eg, ductal stenosis, Figure $\mathbf{3 A}, \mathbf{B}$ and Figure 4A,B) or extraductal calcifications. It is therefore not surprising that $73.1 \%$ of stones not seen with ultrasound alone were located in the distal duct in both glands (Table 2), which highlights the complementary value of sialendoscopy as this is the most easily accessible area of the duct. The option of using transoral ultrasound may be able fill this diagnostic gap, but it requires further investigation. ${ }^{27}$ Manual palpation of the floor of the mouth can also improve the detection rate of salivary stones not visible by sonography, particularly when these are located at the papilla or in the distal duct as pointed out in a recent article. ${ }^{19}$

In cases of false-negative findings, the stones tended to be smaller in the SMG (mean, $2.27 \mathrm{~mm}$ ) than in the PG (mean, $3.0 \mathrm{~mm}$ ). This may be explained by the well-known greater degree of calcification of submandibular stones. ${ }^{28,29}$ Intensive ductal irrigation during sialendoscopy may cause

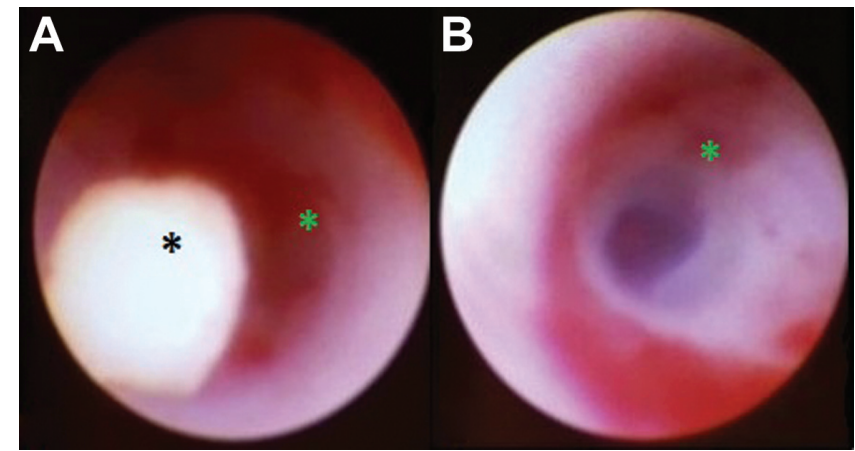

Figure 4. Small stone (black asterisk, $\sim 1.5 \mathrm{~mm}, \mathrm{~A}$ ), visible only by sialendoscopy and located distally to a fibrotic stenosis (green asterisk, A, B), which was the main correlation to the reflex in ultrasound shown in Figure 3.

mobilization of small, mobile, and often peripheral located stones. In unclear cases, after a second ultrasound check after sialendoscopy, these stones may be seen intraductally after mobilization to sonographic favorable sites.

In all false-positive cases, the presence of intraductal sialoliths was excluded using sialendoscopy, and hyperechoism adjacent to the duct was better characterized.

Our results indicate that ultrasound examination should be regarded as a key examination and as the method of first choice for diagnosing sialolithiasis of the major salivary glands. Sonography is performed by the examining clinician before the procedure, during the procedure (interventional sialendoscopy, transoral ductal surgery, and/or ESWL) to confirm or exclude unclear sonographic findings, and immediately afterward to reassess the success of treatment and for follow-up. ${ }^{25,30}$ This dynamic examination sequence is highly cost-effective, does not cause any radiation exposure or contrast administration, and can be repeated as often as needed. For these reasons, it is also suitable for sensitive patients such as children or pregnant women.

It has been shown that direct visualization with sialendoscopy provides additional value to other imaging tools., ${ }^{3,22}$ Koch et $\mathrm{al}^{3}$ investigated over 100 patients with obstructive disease of the major salivary glands that had remained unclear despite various prior imaging procedures, including ultrasound and CT . It was shown that the correct diagnosis of sialolithiasis could be established only by sialendoscopy in $20.8 \%$ of these cases. Vashishta and Gillespie ${ }^{22}$ identified sialolithiasis as the cause of chronic idiopathic sialadenitis in $8 \%$ of cases after performing sialendoscopy. When the ultrasound findings and the sialendoscopy findings were combined, definitive clarification of all false-positive and false-negative findings after the ultrasound examination was possible, and the diagnosis of sialolithiasis could be established or excluded in virtually every case. Sialendoscopy allows direct visualization of the ductal system up to posthilar ducts of the fourth order. In addition, simultaneous treatment for the underlying cause is possible in most cases.

The results achieved with ultrasound examinations alone are comparable with those with the competing imaging 
methods. In earlier publications on the sensitivity and specificity of $\mathrm{CT}$, including $\mathrm{CBCT}$, excellent results were reported. Dreiseidler et $\mathrm{al}^{8}$ reported sensitivity and specificity values as high as $98.85 \%$ after examining 29 patients with sialolithiasis (5 PGs, 24 SMGs), as confirmed by surgical removal of the glands as the gold standard in comparison with a control group of healthy individuals/glands. The authors highlighted examiner independence, reproducibility, and relatively low radiation exposure in the diagnosis of sialolithiasis as advantages of this examination method. The data presented here, including a much larger number of patients, are comparable with those obtained with CBCT but have the advantages offered by ultrasound in comparison with all radiologic modalities. Drage and Brown ${ }^{10}$ showed that CBCT sialography is at least as good as plain sialography. ${ }^{11}$ Digital subtraction sialography alone has been reported to have a sensitivity of $96 \%$ to $100 \%$ and a specificity of around $90 \%$ and is regarded as the gold standard in many studies. ${ }^{7}$

In a study including 123 patients, Kiringoda et $\mathrm{al}^{31}$ also reported that $\mathrm{CT}$ and MRI are able to exclude sialolithiasis in every case, in comparison with sialendoscopy. In small groups of patients not exceeding 25 cases, MR sialography was evaluated by Becker et al, ${ }^{13}$ who described sensitivity, specificity, PPV, and NPV rates of $91 \%, 94 \%$ to $97 \%, 93 \%$ to $97 \%$, and $91 \%$, and by Jäger et al, ${ }^{18}$ who reported a sensitivity of $80 \%$ and a specificity of $100 \%$ for MR sialography with 3D constructive interference in steady-state (CISS) imaging. However, the costs, feasibility in clinical practice, potential for artifacts caused by metallic structures in the vicinity (eg, prostheses), and movement artifacts limit the value of MR sialography. In addition, the stones cannot be visualized directly. When sialendoscopy is used, the minor inadequacies of ultrasonography in diagnosing sialolithiasis can be overcome - although ultrasound already shows a diagnostic value comparable to the best results obtained with $\mathrm{CT}$ and MRI. In comparison with the competing radiologic methods, they are cost-effective, are not associated with risks and side effects such as radiation exposure, and can be performed using local anesthesia. In addition, both diagnostic tools can be used also by the clinician and are valuable for planning, performing the treatment, and checking the success of therapy during the follow-up.

Because deep parenchymal stones are usually not visible by sialendoscopy, we recommend that sonography should be performed initially in all cases of suspected sialolithiasis, followed by sialendoscopy to definitively assess all other locations within the ductal system. Further embedding of ultrasound and sialendoscopy into a practical oriented diagnostic and therapeutic regimen under specific consideration of the cost-effectiveness may be a focus of future research in this field. Limitation of this study is the retrospective design. On the other hand, prospective studies (eg, compare of ultrasound and sialendoscopy with radiologic examination tools like CT scan) are associated with unfavorable side effects/risks and may cause ethical concerns.

\section{Conclusion}

The present results suggest a high diagnostic value of ultrasound for establishing the diagnosis of sialolithiasis. When the findings of ultrasound and sialendoscopy are added, almost every case of sialolithiasis can be adequately assessed. We would therefore propose that ultrasound and sialendoscopy are candidates for use as standard investigation tools in the diagnosis of sialolithiasis. The 2 examination methods represent a substantial part of the armamentarium in our own as in many other units dealing with salivary gland diseases.

\section{Author Contributions}

Michael Koch, substantial contributions to the conception and design of the work; the acquisition, analysis, interpretation of data for the work; drafting the work and revising it critically for important intellectual content; final approval of the version to be published; agreement to be accountable for all aspects of the work in ensuring that questions related to the accuracy and integrity of any part of the work are appropriately investigated and resolved; Miguel Goncalves, substantial contributions to the conception and design of the work; the acquisition, analysis, interpretation of data for the work; drafting the work and revising it critically for important intellectual content; final approval of the version to be published; agreement to be accountable for all aspects of the work in ensuring that questions related to the accuracy and integrity of any part of the work are appropriately investigated and resolved; Konstantin Mantsopoulos, data analysis, revising it critically for important intellectual content, final approval of the version to be published, accountability for the work; Mirco Schapher, data analysis, revising it critically for important intellectual content, final approval of the version to be published, accountability for the work; Heinrich Iro, data analysis, revising it critically for important intellectual content, final approval of the version to be published, accountability for the work.

\section{Disclosures}

Competing interests: None.

Sponsorships: None.

Funding source: None.

\section{References}

1. Al-Nawas B, Beutner D, Geisthoff U, et al. The new S2k AWMF guideline for the treatment of obstructive sialadenitis in commented short form [in German]. Laryngorhinootologie. 2014;93:87-94.

2. Iro H, Zenk J, Koch M. Modern concepts for the diagnosis and therapy of sialolithiasis [in German]. HNO. 2010;58:211-217.

3. Koch M, Zenk J, Bozzato A, Bumm K, Iro H. Sialoscopy in cases of unclear swelling of the major salivary glands. Otolaryngol Head Neck Surg. 2005;133:863-868.

4. Schrøder SA, Andersson M, Wohlfahrt J, Wagner N, Bardow A, Homøe P. Incidence of sialolithiasis in Denmark: a nationwide population-based register study. Eur Arch Otorhinolaryngol. 2017; 274:1975-1981.

5. Sigismund PE, Zenk J, Koch M, Schapher M, Rudes M, Iro H. Nearly 3,000 salivary stones: some clinical and epidemiologic aspects. Laryngoscope. 2015;125:1879-1882. 
6. Sproll C, Naujoks CD. Entzündungen und obstruktive Speicheldrüsenerkrankungen. MKG Chir. 2015;8:128-141.

7. Varghese JC, Thornton F, Lucey BC, Walsh M, Farrell MA, Lee MJ. A prospective comparative study of MR sialography and conventional sialography of salivary duct disease. AJR Am J Roentgenol. 1999; 173:1497-1503.

8. Dreiseidler T, Ritter L, Rothamel D, Neugebauer J, Scheer M, Mischkowski RA. Salivary calculus diagnosis with 3-dimensional cone-beam computed tomography. Oral Surg Oral Med Oral Pathol Oral Radiol Endod. 2010;110:94-100.

9. Rzymska-Grala I, Stopa Z, Grala B, et al. Salivary gland calculi-contemporary methods of imaging. Pol J Radiol. 2010;75:25-37.

10. Drage NA, Brown JE. Cone beam computed sialography of sialoliths. Dento Maxillo Facial Radiol. 2009;38:301-305.

11. Jadu FM, Lam EWN. A comparative study of the diagnostic capabilities of 2D plain radiograph and 3D cone beam CT sialography. Dento Maxillo Facial Radiol. 2013;42:20110319.

12. Goncalves M, Schapher M, Iro H, Wuest W, Mantsopoulos K, Koch M. Value of sonography in the diagnosis of sialolithiasis: comparison with the reference standard of direct stone identification. J Ultrasound Med. 2017;36:2227-2235.

13. Becker M, Marchal F, Becker CD, et al. Sialolithiasis and salivary ductal stenosis: diagnostic accuracy of MR sialography with a three-dimensional extended-phase conjugate-symmetry rapid spin-echo sequence. Radiology. 2000;217:347-358.

14. Terraz S, Poletti PA, Dulguerov P, et al. How reliable is sonography in the assessment of sialolithiasis? AJR Am J Roentgenol. 2013;201:W104-W109.

15. Schwarz D, Kabbasch C, Scheer M, Mikolajczak S, Beutner D, Luers JC. Comparative analysis of sialendoscopy, sonography, and $\mathrm{CBCT}$ in the detection of sialolithiasis. Laryngoscope. 2015;125:1098-1101.

16. Capaccio P, Cuccarini V, Ottaviani F, et al. Comparative ultrasonographic, magnetic resonance sialographic, and videoendoscopic assessment of salivary duct disorders. Ann Otol Rhinol Laryngol. 2008;117:245-252.

17. Kalinowski M, Heverhagen JT, Rehberg E, Klose KJ, Wagner H-J. Comparative study of MR sialography and digital subtraction sialography for benign salivary gland disorders. AJNR Am J Neuroradiol. 2002;23:1485-1492.
18. Jäger L, Menauer F, Holzknecht N, Scholz V, Grevers G, Reiser M. Sialolithiasis: MR sialography of the submandibular duct - an alternative to conventional sialography and US? Radiology. 2000;216:665-671.

19. Larson AR, Aubin-Pouliot A, Delagnes E, Zheng M, Chang JL, Ryan WR. Surgeon-performed ultrasound for chronic obstructive sialadenitis helps predict sialendoscopic findings and outcomes. Otolaryngol Head Neck Surg. 2017;157:973-980.

20. Ching ASC, Ahuja AT. High-resolution sonography of the submandibular space: anatomy and abnormalities. AJR Am J Roentgenol. 2002;179:703-708.

21. Gritzmann N. Sonography of the salivary glands. AJR Am J Roentgenol. 1989;153:161-166.

22. Vashishta R, Gillespie MB. Salivary endoscopy for idiopathic chronic sialadenitis. Laryngoscope. 2013;123:3016-3020.

23. Bozzato A, Hertel V, Bumm K, Iro H, Zenk J. Salivary simulation with ascorbic acid enhances sonographic diagnosis of obstructive sialadenitis. J Clin Ultrasound. 2009;37:329-332.

24. Koch M, Mantsopoulos K, Schapher M, von Scotti F, Iro H. Intraductal pneumatic lithotripsy for salivary stones with the StoneBreaker: preliminary experience. Laryngoscope. 2016; 126:1545-1550.

25. Koch M, Zenk J, Iro H. Algorithms for treatment of salivary gland obstructions. Otolaryngol Clin North Am. 2009;42:1173-1192.

26. Koch M, Schapher M, Mantsopoulos K, von Scotti F, Goncalves M, Iro H. Multimodal treatment in difficult sialolithiasis: role of extracorporeal shock-wave lithotripsy and intraductal pneumatic lithotripsy [published online December 15, 2017]. Laryngoscope.

27. Cho W, Lim D, Park H. Transoral sonographic diagnosis of submandibular duct calculi. J Clin Ultrasound. 2014;42:125-128.

28. Zenk J, Iro H, Klintworth N, Lell M. Diagnostic imaging in sialadenitis. Oral Maxillofac Surg Clin North Am. 2009;21: 275-292.

29. Harrison JD. Causes, natural history, and incidence of salivary stones and obstructions. Otolaryngol Clin North Am. 2009;42:927-947.

30. Zenk J, Koch M, Klintworth N, et al. Sialendoscopy in the diagnosis and treatment of sialolithiasis: a study on more than 1000 patients. Otolaryngol Head Neck Surg. 2012;147:858-863.

31. Kiringoda R, Eisele DW, Chang JL. A comparison of parotid imaging characteristics and sialendoscopic findings in obstructive salivary disorders. Laryngoscope. 2014;124:2696-2701. 